\title{
Textual Reading Comprehension among the EFL Learners
}

\author{
Ibadur Rahman \\ Department of English, King Khalid University, Saudi Arabia \\ Email: ibad79@gmail.com \\ Altaf Jameel \\ Department of English, School of Humanities, Singhania University, India
}

\begin{abstract}
This paper focuses on enhancing comprehensive textual reading skills among EFL learners within an EFL atmosphere by the implementations of very novel techniques. We would like to resolve the concept directly from the reader's point of view instead of plainly preferring the meaning as written in the text, thus manipulating framework for a better reading so that we can be able to generate self-perception and selfmotivation within the target readers.
\end{abstract}

Index Terms - textual reading, motivation, reading comprehension, language classroom, English as a foreign language

\section{INTRODUCTION}

It is a well known fact that the textual readings are the most interesting and universally acknowledged tools of motivation and self-learning. The given context not only provides plenty of opportunities for a reader to understand the pretext but manipulates his own writing in a discourse way by a better concentrative reading. The students enjoy a liberty of expression very openly, thereby enhancing self-comprehension. We are thus supposed to give opportunities where they are able to put their thoughts without any assessment obligations. Obviously a reader is understood as a coparticipant in the transformation of meaning of that text. Thus such a reading gives birth to consciousness (selfrealization) of the reader's personal knowledge he has so far and thereafter its active interaction with the text, he is reading.

Here we shall primarily deal with certain theoretical aspects where overall textual reading is set in. Thereafter we shall throw light on different levels of textual reading. Finally, a conclusion is drawn on the basis of overall classroom assessment. With reference to the textual comprehension, readings are meant:

- To locate problems behind the individual reading activity in an EFL atmosphere/classroom.

- To make a constructive conclusion regarding the role of previous knowledge of the reader's activity.

- To draft a method of reading in a foreign language enhancing the comprehension and interpretation of a text.

\section{COMPREHENSIVE READING STRATEGIES}

The recent tendency contradicts on the use of reading in a foreign language in improving the taste for reading and the student's literacy (Krashen 1993; Manson \& Krashen 1997; Maley 1999; Kern 2000; Day \& Bamford 2000, 2004; Brown 2001). With regards to the textual reading, grammar requirement has remained the basis of necessity besides it demanded nothing from the reader but a passive role in the construction of meaning from the written text. An amazing alternative gets originated within the comprehensive reading principles, the results thus focusing on enjoyment, reading abilities, learning, student's improvement, development of aesthetic taste, enhancing learner's vocabulary, and consolidating grammar like issues. Thus comprehensive reading invites the activity to developing reading skills, vocabulary, writing, linguistic competence and spelling.

In the view of Day and Bamford (2002), the top ten principles for teaching extensive reading are:

1 . The reading material is easy.

2. A variety of reading material on a wide range of topics must be available.

3. Learners choose what they want to read.

4. Learners read as much as possible.

5. The purpose of reading is usually related to pleasure, information, and general understanding.

6. Reading is its own reward.

7. Reading speed is usually faster rather than slower.

8. Reading is individual and silent.

9. Teachers orient and guide their students.

10 . The teacher is a role model of a reader. 


\section{READING APPROACHES AT EFL LEVEL}

The fact that continuous efforts have been made to evaluate as to what happens to a reader while going through the foreign language reading is quite appreciable. The educationists of the fifties and sixties have concluded that the inclination is towards the mother tongue reading process though they threw light on the foreign language. This gave birth to cognitive theories of information after Goodman's publication (1967). "Reading: a psycholinguistic guessing game" Some advised a bottom-up approach of textual meaning in building from the smallest linguistic units to the largest ones. This way a reader is able to gather letters to form words, clauses, sentences and finally a paragraph to evaluate the overall meaning. Here the meaning is carried out for structure de-codification.

Bottom-up processing is decoding individual linguistic units [...] and building textual meaning from the smallest units to the largest, and then modifying preexisting background knowledge and current predictions on the basis of information (Carrel, 1998).

Rest was seen dedicated towards conceptually driven top-down approach encouraging the reader to develop more text predictions. The fundamentals are seen in the scheme theory in reference to which the stored knowledge of the reader helps in the reading comprehension. A Reader draws forecasts and assumptions based on his/her background knowledge. Simultaneously students compare recent information with the previously gained, confirming or refuting his/ her former hypothesis. Thus this approach puts emphasis on reading as comprehension and confirms that it is interpretation oriented as well.

A text contains many gaps; the reader must fill in those gaps, using background knowledge and inference. From this it follows that the result - the gist, or theme, structure - is a product of the text and the reader. (Gough, 1999)

Recently, research has shown interactive approaches with alternate strategies from both bottom-up and top-down approaches in an unpredictable order. The shift from one to the other is in close relation to the reader's interest and objectives followed and the text demands. (Interactive Approaches to Second Language Reading, edited by Patricia L. Carrel, Joanne Devine and David E. Eskey in 1998) An attempt to summarize main interactive approaches more than a decade before, have been developed by the researchers in the said field.

As Nuttall (2000) says it in this way "[...] in practice, a reader continually shifts from one focus to another, now adopting a top-down approach to predict the probable meaning, then moving to the bottom-up approach to check the authenticity of the writer."

\section{THE TEXTUAL READINGS}

The impact of textual reading as a step towards learning a foreign language is taught as recourse to written text. Since the whole focus has been on comprehensive exploration of the given textual form through questions, grammar-based tasks, de-contextualized lexical items, etc., hence the positive role of a reader as a co-creator is sidelined since decades besides the meaning itself has been the result of decoding words significantly. Nowadays, research is carried out on the benefits derived from the implementation of excessive reading to develop reader's literacy. This way textual or article reading emerges as a resource to promote reader's self-perception of the reading (Krashen, 1993; Jiménez Jiménez and Ruiz Cecilia, 2004).The textual readings are mainly heading for expressing freely whatever comes out during the reading process interestingly to emphasize their artistic and self-reflective nature where intrapersonal expectations balance extra textual desires.

Assuming textual reading as motivating tools for the EFL learners, we ought to put emphasis on few arrears that strengthen our approach. Primarily we do acknowledge readers can feel a sort of freedom while reading. The reading turns as habit instead of a compulsion. Textual reading, in this way, emerges as a wonderful resource. Self-perception, innovative thoughts, cognitive conflicts and self-considerations originate freely through the reading process in collaboration of the previously acquired knowledge.

Textual readings are important tools for the overall monitoring of student's comprehension. I $\mathrm{n}$ contrast, a teacher cherishes the opportunity to access important information via the same. Thus provide some hints on how to overcome possible reader's problems what had been the most improving out of the text besides helps in keeping track of the reader's learning capabilities.

Furthermore, reading cultivates an enhancement of critical and metacognitive thinking from readers. They transmit their individual perception of the reading phenomena to the written form thus changing from the mental phenomena of reading to a recursive framework.

Conclusively, there is a desire to unfold the emotional and personal nature, which activates the process of writing and creation of the textual reading. It is absolutely an open model that offers readers the chance to express themselves.

Now let's discuss the phases of designing this textual reading:

\section{A. Contextual Phase}

This phase is totally on to revive the reader's mind and get him back to the original position of reading. This way they can retrieve necessary information and initiate already time-honored plans. We shall put it in four viewpoints space-time, reader's state of mind and bibliographic relevancies. 


\section{B. Pre-textual Phase}

Here the focuses are to uphold student's interest in the text he/she is about to read. The reader utters precisely what he/she thinks would result in the development after textual reading. Meanwhile, they activate previous knowledge, if any, showing some references with the formal portions of the text.

BEFORE READING EXPECTATIONS

- What are your expectations from this reading?

- What do you understand from the title? Does it recall your previous knowledge?

\section{Textual Phase}

This phase is undoubtedly one of the best ideas of reading. Here the text is considered as a multiphase structure where reader's intentions, culture and background knowledge combine with that of the writer's. Here the main focus is on giving meaning to the text written accordingly that interacts with the writer's cognitive plan. The textual phase revolves round the following content fields:

- Formal difficulties

- Implications, experimentations and personal meanings, and

- Interpretations

READING ACTIVITY

- How did you solve problems related to the vocabulary?

- Did you suffer a lot and did you interfere in your comprehension?

$\circ$ During reading, did you translate in your mother tongue?

- Regarding your reading of the text, did you face any sort of difficulty in understanding them?

$\circ$ What do you feel while reading?

$\circ$ What kind of feeling are you experiencing?

$\circ$ How did your previous knowledge help in the interpretation of the text?

$\circ$ What is your real interpretation of the story?

\section{Post Textual Phase}

This is the ultimate phase of textual reading. Here the aim is to put clearly whether the reading was beneficial or not. The readers lay down the contributions and reactions from their personal depth. The readers are supposed to feel free to answer more or less accurately to the questions in the graph. No doubt the reader might have taken pleasure at multiple occasions, but they might have faced problems in translating ideas into words.

WHETHER EXPECTATIONS ATTAINED OR NOT AFTER READING

- What feeling did it create?

- What are your inputs out of the reading?

- Would you really suggest this reading?

\section{TeXtual ReAding AchieVEMENTS AT EFL LEVEL: DesCRIPTION OF PERSONAL EXPERIENCE}

The program was experimented on 17 EFL students (10 girls and 07 boys aged 21 years) of intermediate level of students in Libya, under the recommended guidelines of the oxford university press. As an EFL instructor (2007-2009), he was fully satisfied of their achievements, which were greatly highlighted as they passed their intermediate examination and qualified for the advanced intermediate level. The learners were aimed to become future English teachers. They were asked to read a passage entitled "Importance of English language in Libya". Besides being guided in an open atmosphere, a plenty of time was given which they felt sufficient enough to complete the task. After handing over the written evaluation assignments, the results were outstanding as the feeling and innovative lexical meanings were interpreted reflecting their understanding of the text and enjoying their free and fair atmosphere of expression. The evaluations/examinations were continued for days and finally after about one month, the trial was successfully over.

Debate on Performance

The assignment thus carried out attentively and with sheer enthusiasm, we reached the following conclusions:

A very tranquil atmosphere for reading truly results in easing the interpretation with the complete involvement of overall feelings.

The main obstruction during a reading process arises from the lexical items. Any reading process seems weakening and slows down whenever students come across lexical items in that text. They use reading tactics repeatedly after recognizing the words (guessing 60\%, consulting dictionary 30\%, ignoring words $10 \%$ ) so as to overcome lexical problems. 
As soon as the reader carries on using past experiences and utilize them in the next reading, the interpretation accordingly improves and a new feeling is generated within the reader in the reading process.

The text translation seems inventive during a reading process. Obviously good readers accept it and continue their concentration on difficult passages or where it is demanded in a much comprehensive manner.

\section{CONCLUSION}

Certainly it is a slow and gradual exercise which demands positive involvement and a sense of critical analysis from the reader. The text is a tool to translate ideas, cross-cultural interviews and the participation of reader's own environment. When learners recognize the link between the paragraphs and their own lives, reading turns interesting and understanding seems easier; thus overall reading revolves round different pivots through which reading approaches improve remarkably. New methodologies are born; enthusiasm increases and a habit of continuous reading gets created.

In this paper, we pinpointed certain important reasons as to why we should introduce textual readings in an EFL atmosphere of learning. Textual reading has thus concluded to be a useful method of motivation thereby enhancing and inculcating better reading opportunities of awareness towards learning a foreign language. Our experiment has given vivid feedback. We observed that the learners were very keen to take part in the future reading assignments. They both consciously and unconsciously depicted a sense of freedom during their active involvement in the overall phases of reading.

\section{REFERENCES}

[1] Bamford, J. \& Day, R. R. (1997). stated 'reading has its own reward in terms of its component skills' (p. 6).

[2] Brown, H. D. (2001). 'approach as a language teacher is a set of principles about learning'

[3] Carrel P. L; J. Devine \& D. E. Eskey. (1998). some Causes of Text-boundedness and Schema Interference in ESL reading ( $p$ 101-113): Cambridge university press.

[4] Day, R. R \& Bamford, J (2000). suggest that learners must know at least $98 \%$ of the words. Extensive reading in the second language: Cambridge University Press.

[5] Day and Bamford. (2002). put forward ten top principles for teaching extensive reading in a foreign language, 14/2.

[6] Bamford, J. \& Day, R. (2004). books are the best start in learning more about extensive reading activities for Language Teaching: Cambridge University Press.

[7] Jimenez Jimenez. (2004).Viewed reading as a "trick" for relieving blepharospasm. In D. Madrid \&N. McLaren (Eds.) TEFL in Primary Education (p. 219-243)

[8] Kern, R. (2000). Spoke about Literary texts in the classroom: A discourse 'Literacy and Language Teaching' : Oxford: Oxford University Press.

[9] Krashen, S. D. (1993). The case for free voluntary reading: Englewood Colorado: Libraries Unlimited, Inc.

[10] Maley, A. (1999). Unknown vocabulary density and reading comprehension. Reading in a Foreign Language (p. 3-7).

[11] Nuttall, C. (2000). describes in ELT Chapter 1, what is reading? 'Teaching Reading Skills in a foreign language' Oxford: Macmillan Heinemann.

[12] Manson \& Krashen. (1997). A Fresh Look: Task-based Extended Reading: Extensive reading in English as a foreign language.

[13] Yin Leung C. (2002). A Diary Study of a Beginning Learner of Japanese. Reading in a foreign language (14/1, p. 66-81).

Ibadur Rahman was born in India on February 1, 1969. He got his M.A. in English from Aligarh Muslim University, India in 1998 and CELTA from the University of Cambridge, London 2010. He is currently occupying a Lecturer position in Department of English/ Faculty of Languages and Translation/ King Khalid University / Saudi Arabia/ Abha.

Altaf Jameel got his M.A. in English from Aligarh Muslim University, India in 1998. He has done TESOL from Global TESOL College Canada and has worked as a lecturer of TEFL in Libya (2007-2009). He is currently completing his Ph.D from Singhania University, India. 